\title{
Fallas en la máquina de habitar. Arquitectura, botánica, afecto en Las horas claras de Jacqueline Goldberg*
}

\author{
Flaws in the Living Machine. Architecture, Botany \\ and Affect in Las horas claras by Jacqueline Goldberg \\ Gina SaracenI \\ Pontificia Universidad Javeriana \\ Bogotá, Colombia
}

DOI: https://doi.org/10.32719/13900102.2020.48.3

Fecha de recepción: 20 de febrero de 2020

Fecha de aceptación: 27 de marzo de 2020

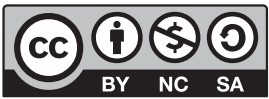

* Agradezco a Juan Cristóbal Castro por sus sugerencias y comentarios durante la redacción de este artículo. 


\section{RESUMEN}

Este artículo tiene el propósito de leer Las horas claras (2013) de Jacqueline Goldberg para mostrar los modos cómo esta novela, mediante su condición "transgenérica", interviene la historia oficial y propone una poética de la no pertenencia a partir del gesto de fisurar el topos de la casa como espacio común del habitar humano, que es también un modo de intervenir el habitar literario descentrando sus límites hacia otras experiencias y saberes como la arquitectura, la botánica y la culinaria. Narrar la vida de una mujer francesa de la primera mitad del siglo XX implica para Goldberg pensar la existencia como un hongo no comestible, como una oronja verde que intoxica y conduce a la muerte. De este modo, su escritura desarticula la jerarquía entre vida humana y vida no humana para mostrar de qué manera lo viviente es también un afecto negativo que opera para la destrucción.

PalABRAS Clave: Jacqueline Golberg, novela venezolana, máquina de habitar, arquitectura, modernidad, mujer, espacio propio, casa familiar, afectos, devenir-vegetal, literatura, micología, planta.

\section{ABSTRACT}

The purpose of this article is to read Las horas claras (2013) by Jacqueline Goldberg as a means to reveal the ways that this novel, through its "trans-gender" condition, intervenes in official history and proposes a poetics of non-belonging based on the gesture of cracking the topos of the house as a common space of human dwelling. This is also perceived as a form of intervening in literary dwelling by decentering its limits towards other experiences and knowledges such as architecture, botany and culinary. For Goldberg, narrating the life of a French woman in the first half of the 20th century, entails thinking of existence as an inedible fungus, as a green grapefruit that intoxicates and provokes death. In this way, her writing breaks down the hierarchy between human and non-human life to show how the living also expresses negative affects that operate to destroy.

KEYWORDS: Jacqueline Golberg Venezuelan novel, living machine, architecture, modernity, women, personal space, family household, affects, becoming-vegetable, literature, mycology, plant.

todo lo que se edifica es una promesa de ruina, lo que se acaba de levantar también. Uno vive rodeado de escombros: habitar casas significa ocupar ruinas.

Sergio Chejfec

\section{ENTRE DESPLAZAMIENTO E INDETERMINACIÓN}

LA PREGUNTA POR la literatura, por su definición y límites ha sido central en la historia de la teoría literaria. En la última década varios críticos latinoamericanos (Josefina Ludmer, Graciela Montaldo, Florencia 
Garramuño, Sandra Contreras, Graciela Speranza, Evando Nascimento, Ticio Escobar, Reinaldo Laddaga, entre otros) se han ocupado de replantear esta interrogante a la luz de la publicación en el continente de una serie de obras — poesía, narrativa, crónica, memoria, arte, fotografía - que hacen de la forma literaria un lugar de expansión, contagio y acercamiento de saberes, lenguajes, formas, géneros. Se asiste a un constante desplazamiento de "las nociones de pertenencia, individualidad y especificidad" (Garramuño 2015, 13), tanto en lo que se refiere a los soportes y formatos de la literatura como a los sensorios, conocimientos, experiencias que allí se ponen en escena. La desterritorialización de medios y temas, el desbordamiento de fronteras - discursivas, epistémicas, de género-, la inclusión de distintos materiales en un mismo espacio estético, la expansión del campo literario, el cuestionamiento del canon, definen la práctica literaria que cada vez es más “errante” (Speranza 2012), “fuera de sí” (Escobar 2014) y un umbral entre obra y vida, vida y cultura, archivo e historia.

Quiero partir de este debate sobre la inespecificidad, errancia y apertura de la literatura y el arte, para abordar el proyecto estético de la escritora venezolana Jacqueline Goldberg (Maracaibo, 1966), poeta, periodista, ensayista, autora de una vasta producción literaria constituida por los siguientes libros: Treinta soles desaparecidos (1985), De un mismo centro (1986), En todos los lugares, bajo todos los signos (1987), Luba (1988), A fuerza de ciudad (1990), Máscaras de familia (1991), Trastienda (1992), Insolaciones en Miami Beach (1995), Vispera (2000), La salud (2002), El orden de las ramas (2003), Autopsia, Verbos predadores (2007), Postales negras (2011), Día del perdón (2011), Limones en almibar (2014), Nosotros, los salvados (2015), Perfil 20 (2016), El cuarto de los temblores (2018), Las bellas catástrofes (2018).

Su obra se caracteriza por la indeterminación discursiva y el desplazamiento entre diferentes géneros y formatos: la poesía documental, el reportaje, el periodismo, la crónica, la narrativa infantil, la dramaturgia, la novela poética, el blog, el periodismo culinario. Hay un ejercicio constante de parte de la autora, de tensar los límites entre ficción, documento, invención, autobiografía, para propiciar intercambios y contagios entre ellos, y mostrar cómo la literatura es más un espacio de confluencia y convivencia que de definición y precisión. De allí que el mismo ejercicio literario se vuelva un gesto de apropiación, intervención y reescritura de documentos y datos pertenecientes a archivos de la historia y la cultura y que, al ingresar a la literatura, adquieren otras posibilidades de significación y circulación. 
Goldberg reconoce como influencias centrales de sus elecciones estéticas a Marguerite Duras, Amélie Nothomb, Anne Carson, Chantal Maillard, Hermann Broch, Mario Bellatin, autores que, de distintas maneras, ponen en crisis la noción de especificidad al desestabilizar las fronteras y las determinaciones de formas, géneros y saberes, y al poner en escena modos de hacer y de sentir pertenecientes a sensorios no siempre instituidos.

Sobre su apuesta estética dice Goldberg en una entrevista:

Documentación es un vocablo que me interesa muchísimo. De hecho, he venido trabajando en varios libros con "poesía documental", término que no inventé y que me permite estructurar como poesía temas y textos históricos y periodísticos [...]. "extraer poemas de una noticia". En eso creo y con tal materia trabajo. Por eso fue muy natural llevar todo lo investigado sobre Le Corbusier y la Villa Savoye a un lenguaje poético y sumergirlo incluso en algo de ficción. Siento que carezco de dones para la ficción, no sé, no puedo inventar historias. Solo me siento realmente segura reinventando la realidad que leo, partiendo de documentos. (Goldberg, en Payares 2014)

Escribir para reescribir, para editar - documentos, testimonios, noticias - es uno de los procedimientos al que recurre la autora, así como a la investigación y al reportaje como prácticas que posibilitan la búsqueda y hallazgo de hechos que se vuelven materiales para "extraer poemas". Ese tránsito entre documentos de la historia y la cultura, y su reelaboración mediante el ejercicio literario en sus diferentes posibilidades, constituye un rasgo definitorio de la obra de Goldberg que, de este modo, desmarca la noticia, el suceso, la cita, la imagen de su espacio de aparición (archivo, periódico, literatura, arte) para reescribirla y darle otra significación.

Sus libros Autopsia, Nosotros los salvados, Cuarto de temblores son ejemplos de este ejercicio de cooperación de formas y conocimientos donde las noticias de crónica roja, los testimonios de los judíos que emigraron a Venezuela, la enfermedad y sus diagnósticos respectivamente, se convierten en ocasiones poéticas para mostrar otros modos de construcción del sentido. El de Goldberg es un proyecto que piensa la literatura como un cuerpo de saberes y discursos de la cultura y de la vida, un cuerpo inestable y propenso al devenir y a la mutación de sus soportes y lenguajes. De allí la necesitad de experimentar en cada obra nuevas posibilidades de nombrar la experiencia y la literatura misma no para definirla sino, por el contrario, para expandir sus posibilidades y combinaciones. 
Esta manera de entender la literatura como espacio de conexión entre géneros, tradiciones, formas y como lugar de transición entre vida y obra, vincula el proyecto de Jacqueline Goldberg con apuestas estéticas de otras escritoras venezolanas y latinoamericanas de las últimas dos décadas como: Victoria de Stefano, Verónica Jaffé, Gabriela Kizer, Claudia Sierich, Mariela Casal, Carolina Lozada, Natasha Tiniacos; Sylvia Molloy, Tamara Kamenzain, Matilde Sánchez (Argentina); Cristina Rivera Garza, Sara Uribe (México), Ana Paula Maia (Brasil), Diamela Eltit, Eugenia Brito, Lina Meruane (Chile), Liliana Colanzi (Bolivia), Marta Aponte Alsina (Puerto Rico), por mencionar algunas. En todos los casos, más allá de la especificidad propia de cada autora, se trata de prácticas de resistencia a los modos oficiales y hegemónicos de relatar el pasado, el cuerpo, el poder, la memoria, mediante la instalación en el texto de restos y fragmentos de historias que proponen otros modos de recordar, otros materiales para el relato y otras lógicas de representación.

Estas prácticas estéticas, según Florencia Garramuño (2015) en su libro Mundos en común:

Parecen compartir un mismo malestar frente a cualquier definición específica o cualquier categoría de pertenencia en la cual cómodamente instalarse. Prácticas fundamentalmente ágiles y dinámicas atraviesan el paisaje de la estética contemporánea con figuras diversas, a menudo difíciles de categorizar y de apresar de la no pertenencia. [...]. Estas prácticas han transformado el paisaje de la estética contemporánea de un modo radical propiciando modos de organización de lo sensible que ponen en crisis ideas de pertenencia, especificidad y autonomía (23). [...]. La apuesta por lo inespecífico no es hoy -como tal vez no lo fue nunca - solo una apuesta por la inespecificidad formal, sino un modo de elaborar un lenguaje de lo común que propicia la invención de modos diversos de la no pertenencia. (19, 23, 26; cursivas en el original)

A partir de los planteamientos anteriores, este artículo tiene el propósito de leer Las horas claras (2013), de Jacqueline Goldberg, para mostrar los modos en que esta novela, mediante su condición transgenérica, interviene la historia oficial y propone una poética de la no pertenencia a partir del gesto de fisurar el topos de la casa como espacio común del habitar humano, que es también un modo de intervenir el habitar literario descentrando sus límites hacia otras experiencias y saberes como la arquitectura, la botánica y la culinaria. Narrar la vida de una mujer francesa de 
la primera mitad del siglo XX implica para Goldberg pensar la existencia como un hongo no comestible, como una oronja verde que intoxica y conduce a la muerte. De este modo, su escritura desarticula la jerarquía entre vida humana y vida no humana para mostrar de qué manera lo viviente es también un afecto negativo que opera para la destrucción.

En este sentido, la novela también propone, como se verá más adelante, la idea de la casa como una alegoría del fracaso del proyecto moderno que concibe el hogar como refugio existencial, como propiedad y garantía material y simbólica. Frente al presupuesto de una pertenencia "humana" que pasa por una estructura y construcción material, se impone la vivencia natural al margen de lo humano, el devenir-vegetal que fisura la casa moderna como posibildiad de arraigo y seguridad, y desarticula el discurso de la especie.

De esto se desprende una posible relación entre el carácter no específico de la obra de Jacqueline Goldberg y una poética de la no pertenencia que apuntan ambas a un estado de dispersión y diseminación más que de sujeción y estabilidad del sujeto.

\section{CONSTRUCCIÓN / DESTRUCCIÓN: ARQUITECTURA / RUINA}

La casa es una mancha de la que brotan raices Jacqueline Goldberg

Las horas claras transita entre el documento histórico, el reportaje, la memoria y la ficción poética. Fue ganadora del XII Premio Transgenérico de la Sociedad de Amigos de la Cultura Urbana (2012), después de varios intentos, por parte de la autora, de buscar editoriales — nacionales e internacionales - que se interesasen en publicarla y que la rechazaron por considerarla "poco comercial" a causa de su indeterminación formal y su temática.

El jurado calificador del concurso — constituido por Joaquín Marta Sosa, Héctor Torres y yo- se expresó de esta manera sobre el libro ganador: 
Es una obra contundente tanto por el modo como aborda el tema del habitar, de lo irrecuperable, de la pérdida a través de referencias a la arquitectura y la historia, como por su apuesta formal que se arriesga a cruzar géneros diversos con un estilo y lenguaje de una alta calidad literaria. Se trata de un texto transgenérico en sus modos de cruzar referencias, materiales, tradiciones, géneros, y de una indiscutible originalidad. En definitiva, es un extrañísimo, hermoso, inclasificable híbrido que une poesía, historia y novela. (157)

El otorgamiento del premio hizo que finalmente la obra se publicara en la editorial de la Sociedad de Amigos de la Cultura Urbana, en el número 107 de la colección. Ese mismo año le fue dado el Premio Libro del Año para narrativa, concedido por los Libreros Venezolanos, como también la Medalla Internacional Lucila Palacios del Círculo de Escritores de Venezuela y fue finalista, en 2014, del Premio de la Crítica a la Novela del año en Venezuela.

Cabe destacar aquí la existencia de una tradición poética en la poesía venezolana sobre la casa, que tiene en la poesía escrita por mujeres sus mejores propuestas, como ocurre con la obra de Enriqueta Arvelo Larriva, Luz Machado, Antonia Palacios, María Fernanda Palacios, Yolanda Pantin, Gabriela Kizer, Beverly Pérez Rego, Carmen Verde, por mencionar algunas. Este libro de Goldberg propone otro modo de pensar la casa y escribirla que se distancia de estas otras poéticas existentes en Venezuela.

La novela está dividida en diez partes y tiene 109 capítulos; la última parte, "Las horas vistas", está constituida por siete fotos en blanco y negro de la villa y también se incluyen, antes del final, una carta de 1937 en edición facsimilar que Madame Savoye le escribió a Le Corbusier quejándose de su desinterés por el deterioro de la casa, y un texto titulado "Los hilos que conducen a la realidad", donde Goldberg hace referencia a los documentos y los libros ${ }^{1}$ que le sirvieron para escribir la novela: "Solo dos cartas de las que Madame Savoye dirige al arquitecto Charles Edouard Jeanneret son ficticias [...]. Todas las demás son misivas auténticas de Eu-

1. Goldberg al final de las Horas claras coloca un texto titulado "Los hilos que conducen a la realidad", donde se refiere a las fuentes que consultó y usó para escribir el libro: "Documento fundamental para conocer los vericuetos de la venta y declaración de patrimonio de la villa Savoye fue el trabajo 'The Villa Savoye and the modernist Historic Monument', de Kevin F. Murphy (The Journal of the Society of Architectural Historians", vol. 61, n. ${ }^{\circ}$ [marzo 2002]: 68-89" [142]). 
génie Savoye, traducidas por mí de los manuscritos en francés enviados gentilmente desde París vía internet por la fundación Le Corbusier” (142).

Las horas claras narra la historia de Eugénie Thellier de La Neuville, más conocida como Madame Savoye, una mujer de la clase alta parisina que en 1928 contrata al arquitecto Charles Edouard Jeanneret, conocido como Le Corbusier, para que realice su casa de verano en las afueras de París. Terminada la casa en 1929, ella y su esposo la habitan por temporadas durante cinco años hasta que comienza a deteriorarse por una avería en la estructura que causa que llueva adentro; Madame Savoye le escribe al arquitecto pidiéndole ayuda para resolver la falla, pero este por años no le responde. Con la llegada de la Segunda Guerra, la mujer regresa a París, la casa es ocupada por los nazis y después expropiada hasta que Le Corbusier, a finales de los cincuenta, realiza una campaña internacional de apoyo para salvarla y restaurarla. Madame Savoye, después de haber postergado por años su regreso a la villa, decide volver y allí muere a causa de la ingesta de una seta venenosa.

$\mathrm{Si}$, por un lado, la novela puede leerse como la historia de una casa hecha por uno de los arquitectos más importantes de la modernidad y que transcurre durante y después de la Segunda Guerra Mundial; por el otro - y es la lectura que quiero proponer - es la historia de una vida: la vida de una mujer que busca una pertenencia, un espacio propio y que, por eso, construye una casa "para ser en ella" (32), para no extraviarse. El texto inicia con la rememoración del pasado por parte de Madame Savoye, anciana quien, desde las primeras páginas, aparece como un cuerpo atormentado por la desesperanza y la impotencia, dominado por el espectro de la muerte y la destrucción, cuya existencia está definida por la necesidad de pertenecer y "salvarse del desierto" (27). Se trata de una mujer que "Deseó una villa como una fe" (27), no por la falta de un techo donde vivir ni tampoco porque quería convertirla en una casa de campo para la familia; sino, por el contrario, para tener una casa lejos de su residencia de París donde vivía con el esposo y el hijo, que le permitiera alejarse de las rutinas de la vida burguesa y patriarcal: "Nuestras casas nos desagradan; huimos de ellas y frecuentamos los cafés y los bailes; o nos congregamos taciturnos y agazapados, en las casas, como animales tristes, nos desmoralizamos"2 (32). Madame Savoye es "un animal triste" que no encaja en los

2. Este fragmento forma parte de un diálogo con el arquitecto en el que Le Corbusier dice: "Nos hemos convertido en animales sedentarios; la casa nos roe en nuestra 
roles de madre y esposa que la sociedad y la moral burguesas le asignan a la mujer en la primera mitad del siglo XX y que, a pesar de desempeñarlos y padecerlos, actúa en contra de ellos y de su violencia simbólica. Su cuerpo encarna una sensibilidad desajustada respecto de su tiempo, arrojada a una intemperie existencial que la aparta de la economía de los afectos dominantes y la vuelve una mala hierba que solo puede fugarse de los caminos trazados y rectos tras la búsqueda de la intensidad de la luz y de la belleza.

Entre las imágenes que Gilles Deleuze y Félix Guattari usan para pensar la literatura están la hierba y el rizoma, especies botánicas que crecen en medio de las cosas y que tienen "direcciones cambiantes [...], líneas de fuga y de desterritorialización", y que "no tienen principio ni fin", sino que "siempre tienen un medio por el que crecen y desbordan" (Deleuze y Guattari 1994, 25).

Pensar la literatura como hierba y rizoma implica entenderla por fuera de un sistema reconducible a una unidad o sistema explicativo del mundo, como un movimiento de variación, interrupción y devenir siempre inacabado y antigenealógico. La literatura entonces como un ejercicio de huida de la ruta mayor y dominante, un camino en zigzag que no inicia ni termina, sino que funciona en el medio según la lógica de la conjunción, del estar entre las cosas. "No es fácil ver la hierba en las palabras y en las cosas", dicen Deleuze y Guattari (27), y con esto señalan la dificultad que supone pensar/escribir en ese entre incómodo e indeterminado que es la hierba sin recurrir a un esquema arborescente de imitación, explicación, reproducción del mundo: "Sabiduría de las plantas: incluso cuando tienen raíces siempre hay un afuera en el que hacen rizoma con algo: con el viento, con un animal, con el hombre" (16-7).

Quiero pensar a Madame Savoye como una hierba que se fuga de París para hacer rizoma con la luz, las plantas, el aire y devenir en otras formas de lo viviente. Desde el inicio de la novela aparece como un personaje atormentado por la desesperanza, "la ausencia de lugar" (Goldberg 2013, 31), en conflicto con su vida que, si bien le permite tener lujos y comodidades, es insuficiente para colmar una falta que la constituye desde la infancia y que se manifiesta a través de una pulsión de muerte y destrucción: "Nadie supo jamás de los amagos suicidas de Eugénie Thellier de La Neuville” (16):

inmovilidad, como una tisis. Dentro de poco necesitaremos demasiados sanatorios" (Goldberg 2013, 32). 
[...] su exilio crujía bajo la piel [...]. El nacimiento en 1907 del hijo Roger, desató en ella un bestiario: repentino e inquietante carnaje. Se volvió distante, con dobleces y escalofríos. Se hizo completamente vieja. Fue entonces cuando comenzó a desear una villa a la que llegar con su propio automóvil, ataviada de enormes sombreros, lentes de sol. Con la maternidad sobrevino también la necesidad de luz, una rutina de verdores, asuntos culinarios. Se trataba de conciliar placer y tristeza, vocerío y eternidad. (29)

Entre la depresión y la exaltación, Madame Savoye decide encargarle al arquitecto Le Corbusier el diseño y realización de la maison de champagne, lo que significa una apuesta por una concepción nueva y moderna del espacio basada en los principios de comodidad y funcionalidad, así como de racionalización, industrialización y prefabricación. Estos debían servir, según su apuesta, para hacer más cómoda la vida de sus ocupantes mediante la incorporación en la vivienda de adelantos técnicos de la época. "Máquina de habitar" (machine a habitér) fue la denominación que Le Corbusier le dio a esta nueva arquitectura que utilizaba el cemento armado como material principal de construcción, y que elevaba las casas del suelo a través de columnas (pilotis) y le colocaba techos planos que cumplían la función de jardines elevados que permitían estar al aire libre dentro de la casa.

La parte de la novela titulada "Las horas edilicias" registra diferentes etapas de la construcción de la villa y fragmentos de una carta que Madame Savoye le manda a Le Corbusier, con un "listín de apremios" que ella desea que se tomen en cuenta en la realización de la casa:

En principio quisiera que fuera posible agrandarla dentro de algunos años sin que ese crecimiento arruine la casa. Debe haber agua caliente y fría, gas, calefacción central.

En la zona con calefacción: una gran pieza de doce metros, un vestier (lavabo, poceta), una cocina, una oficina, un frutero, una habitación para dormir de cinco metros, otra habitación de dormir de cuatro por cuatro, separadas por una sala de baño.

En la planta alta: una habitación de cinco metros con una sala de baño cerrada, una lencería, un vestir de quince metros cuadrados.

Servicio: dos habitaciones de servicio con lavamanos y poceta, un garaje para tres automóviles, un alojamiento de conserje y un alojamiento de chofer (un cuarto para escobas y un granero). Una cava de vino y otra cava. 
Detalles: una cocina como la de la villa de Torcay, con tres neveras de corriente y dos lámparas. Un estudio un poco más grande que el de aquella villa, un espacio para la caldera eléctrica y una nevera de corriente. Un vestier más grande con una lámpara de plafón y otra de lavabo. En la habitación grande, luz indirecta y lámparas. Sobre la mesa para comer, una gran chimenea. No hace falta que esta sala sea estrictamente rectangular, pero sí confortable. Una habitación para dormir, cinco por cuatro, para mi hijo, que sea la habitación y estudio con iluminación en la cama, en el escritorio y un tomacorriente en medio. Sala de baño con un gran vidrio contra el juro y un alumbrado aparte [...]. (34; subrayados en el original)

Como se observa en la cita anterior, Madame Savoye reproduce en su carta los fundamentos de la concepción lecorbusiana de la arquitectura como un saber sobre el espacio y las estructuras, pero también como "el encuentro entre la luz y la forma", como "un fenómeno de emociones que queda fuera y más allá de las cuestiones constructivas". ${ }^{3}$

De esto se desprende que la arquitectura también funciona como sensorio que propone nuevos modos de habitar el espacio. Las horas claras, ${ }^{4}$ así denominada por Madame Savoy, es una casa que ofrece no solo una experiencia de la comodidad y del confort moderno, sino además es pensada como "máquina de la felicidad" que repercute en la forma de vida de sus ocupantes a través de sensaciones que son el resultado de una relación de continuidad y conexión entre el espacio interior y el exterior de la casa.

Cabe destacar que en la novela hay una referencia a la escritora Victoria Ocampo, a quien Le Corbusier conoció durante un viaje a Argentina a final de los años veinte, y a quien menciona en una carta que le manda a Madame Savoy:

He estado en Buenos Aires y en un balneario llamado Mar del Plata. He visto allí las casas que ha hecho construir una poeta. Oyéndola a ella la recordé a usted y nuestro proyecto, porque Madame Victoria no se cansa de explicar que quería que los árboles y el cielo entraran en la casa, que buscaba espacio, paredes blancas y desnudas, capaces de forjar un fondo tan neutral y tan claro que todo fuese fiesta para los ojos: el color de la cubierta de un libro, el amarillo de un sombrero sobre la

3. http://www.arqpress.net/index.php/paginas/ver/219.

4. Las horas claras es un verso del poeta belga Émile Verhaeren. 
mesa, una flor en un vaso, una mancha de cielo azul reflejada en el espejo. ${ }^{5}$ La casa de Victoria Ocampo en Mar del Plata es un cubo blanco y austero, de terrazas que dan al sol y al mar; encontré allí obras de Picasso y Léger en el marco de un purismo que raramente he visto hasta ahora. Madame Ocampo tiene una concepción clara de la arquitectura; no le importan las críticas que dicen que la suya es la casa más fea de la ciudad. Claro, ella ha hecho un gesto decisivo para la arquitectura: construir una casa escandalosa. (Goldberg 2013, 39)

La mención a una de las figuras más destacadas del campo intelectual y literario argentino, apasionada por la arquitectura moderna y admiradora de Le Corbusier, da cuenta de una relación singular de las mujeres de la primera mitad del siglo XX con la casa, basada no tanto en una concepción doméstica de este espacio, sino más bien en una visión renovada de las estructuras, la distribución y el mobiliario, con la finalidad de posibilitar otra experiencia del habitar basada en sensaciones y emociones nuevas.

Así como para Victoria Ocampo, para Madame Savoy la villa que Monsieur Jeanneret le diseña es un espacio para imaginar y experimentar modos de habitar el espacio relacionados con otras formas de la construcción y con la influencia de la luz en el modo de vivir y de sentir de aquellos que la ocupan. ${ }^{6}$ Una casa que salva del desierto parisino y posibilita otra circulación de los afectos que fomenta en su dueña una sensibilidad más próxima a la poesía, a la hierba, a la campiña, a la naturaleza, que la alejan de la vida urbana y burguesa.

Así como en los primeros cinco años después de su construcción, villa de Poissy le proporciona a su dueña una experiencia renovadora de la casa como "máquina para vivir"; al poco tiempo su estructura se comienza

5. Dice Victoria Ocampo: "Me gustan las casas vacías de muebles e inundadas de luz. Me gustan las casas de paredes lacónicas que se abren, dejando hablar al cielo y a los árboles". También añade: "La casa que, en efecto construí en Mar del Plata con un simple constructor que, por lo demás, gustó a Le Corbusier, fue hecha de acuerdo a mis indicaciones, tanto por fuera como por dentro. Yo la quería absolutamente simple, absolutamente desnuda. Quería recomenzar todo lo relativo a la arquitectura y al amoblamiento a partir de cero, después de haber hecho tabla rasa como todo lo que había aceptado hasta ese momento" (1982).

6. Le Corbusier se refiere a la relación entre arquitectura y luz en los siguientes términos: "La arquitectura es el juego sabio, correcto y magnífico de los volúmenes bajo la luz. Nuestros ojos están hechos para ver las formas bajo la luz; las formas y los claros revelan las formas" (Goldberg 2013, 97). 
a enfermar a causa de una filtración que, desde el jardín pénsil, invade las paredes con una lluvia que "golpea hacia adentro, incontenible" (64):

Un día, sin más comienza la tragedia.

Gotas.

Gotas.

Gotas.

Gotas que marcan pozos en las esquinas, que surcan el aire, se desplazan, planean sobre los pisos.

Gotas de plenilunio, de frío.

Gotas ensimismadas, criminales.

Gotas ovíparas, ciclópeas, feroces.

Gotas opulentas,

Gotas sin mensaje.

Gotas. (63)

La aparición de la falla en la obra de Le Corbusier pone al desnudo una avería en la misma concepción moderna de la arquitectura que funciona como una resistencia al orden de la cultura y de la historia. El agua con su goteo persistente ("llueve en la entrada, llueve en la rampa y el muro del garaje está absolutamente mojado [...] llueve siempre en mi baño, que se inunda con cada lluvia. El agua pasa por la claraboya del cielorraso. El agua también se escurre por la jardinera", (65) convierte la "máquina de habitar" en una ruina; hace que la construcción se ponga en peligro a sí misma y se ahogue en la humedad de sus paredes.

George Simmel, en un ensayo titulado "Las ruinas", reflexiona sobre la relación entre arquitectura y naturaleza, y observa:

La arquitectura es el único arte en el que se salda con una paz auténtica la gran contienda entre la voluntad del espíritu y la necesidad de la naturaleza, en el que se desenvuelve en un equilibrio exacto el ajuste de cuentas entre el alma, que tiende a lo alto, y la gravedad, que tira hacia lo bajo. En la poesía, la pintura o la música las leyes del material no pueden sino servir calladamente a la idea artística [...] La arquitectura, en cambio, aunque utiliza y distribuye el peso y la resistencia de la materia de acuerdo con un plan que solo puede haber emergido del alma, permite que dentro de este la materia actúe según su naturaleza inmediata, ejecutando ese plan como con sus propias fuerzas. Es la más sublime victoria del espíritu sobre la naturaleza, similar a la que se consigue cuando se logra dirigir a una persona de tal manera que cumpla nuestros deseos sin necesidad de forzar su propia voluntad, 
sino obedeciendo simplemente a esa, haciendo que la dirección de sus impulsos personales se ajuste a nuestro plan.

Sin embargo, este equilibrio único y singular entre la materia inerte, sujeta a leyes mecánicas y que resiste pasivamente a la presión que se ejerce sobre ella y la espiritualidad formadora que tiende a lo alto, se quiebra en el momento en que el edificio se degrada y se desmorona. Pues esto no significa sino que las fuerzas meramente naturales empiezan a enseñorearse de la obra del hombre: el equilibrio entre naturaleza y espíritu que representaba la arquitectura cede a favor de la naturaleza. [...] pues en ese momento la ruina aparece como la venganza de la naturaleza por la violencia que le hizo al espíritu al conformarla a su propia imagen. [...] En el momento en que el desmoronamiento del edificio destruye la plenitud de la forma, ambos componentes vuelven a disociarse y ponen al descubierto su originario y universal antagonismo. Parece entonces como si la configuración artística no hubiera sido más que un acto de violencia del espíritu al que la piedra se hubiese sometido contra su voluntad, como si ahora se sacudiera poco a poco a ese yugo y retornase al imperio independiente de sus fuerzas. [...] las ruinas arquitectónicas indican que en las partes desaparecidas o destruidas de la obra de arte han hecho acto de presencia otras fuerzas y formas, las de la naturaleza, de tal manera que lo que subsiste todavía en ella de arte y lo que ya hay en ella de naturaleza, constituyen una nueva totalidad, una unidad característica [...]. El encanto de la ruina consiste en que una obra humana es percibida, [...] como si fuera un producto de la naturaleza. (2002, 181-5; las cursivas son mías)

En esta cita Simmel plantea una tensión entre construcción y degradación, obra humana y fuerzas no humanas, espíritu y naturaleza, arte y violencia. El devenir-ruina de la villa Poissy, su devenir mineral (agua) y vegetal (raíz, hongo) pone en crisis los límites trazados por el humanismo y la máquina antropológica, y muestra la resistencia de la naturaleza, el defecto de la arquitectura moderna y su fracaso. Madame Savoye le suplica en múltiples cartas a Le Corbusier que se ocupe de la avería de su casa, y este no le presta atención. Así como el agua llueve adentro de la casa, de la misma forma la rabia y la venganza enferman el cuerpo de la mujer habitado por un "vacío congénito" desde la infancia, hasta envenenarlo y volverlo una ruina más de la casa, una mala hierba.

La vida y obra humanas en Las horas claras constituyen la zona ciega de la modernidad donde los umbrales se vuelven lugares de tránsito y contagio, y no de separación y clasificación: "No se trata de la vida de alguien”, observan Gabriel Giorgi y Fermín Rodríguez en el "Prólogo" 
a Ensayos sobre biopolitica. Excesos de vida (Agamben 2007), "sino de un flujo de pura vida despojada de su soporte humano que a la manera de una última ola en los límites del mar, borra de la arena el rostro del hombre, llevándose, en su reflujo, percepciones y afectos flotantes impersonales que ya no pertenecen a nadie" (Goldberg 2013, 16).

En este sentido quiero proponer que el último devenir de Madame Savoye post mortem, además del devenir-vegetal que mostraré a continuación, es su devenir-luz-onda-partícula electromagnética que se esparce entre y dentro de las cosas y flota entre las ruinas de la cultura.

\section{LITERATURA Y MICOLOGÍA}

solo en las afueras de la vida se puede plantar una pequeña ilusión Vicente Huidobro

En Las horas claras hay una zona menor, casi secreta, que da cuenta de un afecto fundamental entre Madame Savoye y las setas: se trata de una alianza entre especies - humana y no humana-, de una relación de contagios y devenires que muestra un desborde de la vida de la protagonista hacia otras formas de lo viviente, donde el organismo vegetal se convierte en espacio de agenciamiento y desvío de lo humanamente reconocible. Una vida más allá de lo humano, en estado de variación e intensidad permanente que, como la hierba, se desplaza en medio de las cosas.

Madame Savoye es una mala hierba que interrumpe su arbórea existencia burguesa para hacer familia con otras formas de lo viviente, como los hongos que comunican a los árboles entre sí a través de filamentos que generan una red de conexiones e interacciones entre raíces y tallos. ${ }^{7}$ Esto se observa desde el primer y segundo capítulo de la novela, que nos

7. En el artículo "Cómo amar a un hongo", Anna Tsing dice: "Si pudieras, de alguna manera, bajar a la tierra, te encontrarías rodeado por la arquitectura de redes y filamentos de esta ciudad. Los hongos tejen esas redes para interactuar con las raíces de los árboles, formando articulaciones llamadas micorrizas. Las redes de micorrizas no solo conectan hongo y raíz (myces-rhiza), sino que comunican árboles y árboles a través de los filamentos de los hongos, enlazando todo el bosque con líneas directas, enredándolo. Esta ciudad es una escena vívida de acción e interacción". https://elmalpensante.com/articulo/3519/como_amar_a_un_hongo. 
introducen en un espacio vegetal marcado por la presencia amenazante de la "oronja verde":

1.

Desde mediados de verano hasta bien entrado el otoño, hayedos y robledales se abarrotan de oronjas verdes. Desorientados buscadores de setas suelen confundirlas con especies comestibles.

De sugerente apelativo científico, Amanita phalloides, su sombrero globoso, está envuelto por un velo blanquecino que trasluce una coloración a veces amarilla verdusca. La superficie es sedosa en sequía y un poco viscosa tras la lluvia. El pie, esbelto, cilíndrico, firme, casi liso. Su carne, de un débil olor, en ejemplares vetustos se torna desagradable. Quienes han sobrevivido a la ancestral prohibición de paladear esta especie dicen que su sabor es dulce, [...] como la crema chantillí o el algodón de azúcar.

Bastan cincuenta gramos de una oronja verde para devastar a un adulto.

Horas después de su ingestión acaece el suplicio. Aparecen náuseas, vómito, dolores abdominales, deshidratación, insuficiencia renal y una violenta hemorragia. Luego se producirán hemorragias y una severa hepatitis.

Con la rauda intoxicación sobrevendrá la marejada de la muerte y el arrepentimiento, ya inútil, de haber convocado la belleza. (Goldberg 2013, 13)

2.

La perfecta morbidez de las setas procede de un reino aparte. Algo de su maldad seduce. Su pecado está en anidar en diminutos cadáveres y restos orgánicos, en someterse a la hospitalidad de los troncos. (14)

La literatura como micología es una de las lecturas posibles de esta novela que comienza con la descripción de la fisiología de una especie vegetal no comestible, de su hábitat y de los efectos que causa su veneno en el organismo humano al ser ingerida; para después desorganizar el mismo discurso científico y tensarlo hacia un más allá afectivo y simbólico donde la seta es un modo de lo viviente y también de su destrucción. Mujer y planta se conectan, se contagian, se comunican de forma subterránea y transversal; constituyen un rizoma que crece "entre los espacios no cultivados”, lejos de París y de la vida urbana, y que desborda el orden familiar y social como también sus rituales y convenciones. Un rizoma que es "una circulación de estados" (Deleuze y Guattari 1994) indeterminados y diseminados, que desarticulan la arquitectura de una vida planificada y 
medida para llevarla hacia un afuera vegetal y conectarla con la naturaleza y sus hongos mortales. Mujer-oronja constituye un estado de la novela que se manifiesta de modo atenuado, casi imperceptible, como crecen los hongos entre los troncos del bosque. Se trata de una micropolítica que intoxica todo intento de la modernidad de darle una forma racional al deseo, y todo intento de la misma máquina de escribir de reconducir la literatura a un sentido organizador: "El medio [...] es el sitio por donde las cosas adquieren velocidad. Entre las cosas no designa una relación localizable que va de la una a la otra y recíprocamente, sino una dirección perpendicular, un movimiento transversal que arrastra a la una y a la otra, arroyo sin principio ni fin que socava las dos orillas y adquiere velocidad en el medio" (29).

$\mathrm{Si}$, por un lado, Las horas claras narra la historia de una villa hecha por Le Corbusier y las consecuencias que esta construcción causa en la vida de su dueña; por el otro, es la historia de un relato secreto que crece fuera de los muros de la casa y de la arquitectura moderna, en el borde de lo humano, fuera del biopoder y sus taxonomías, fuera de la máquina antropológica, lejos de las prácticas y rituales modernos, cerca de las entrañas de la tierra, entre la red de filamentos que las raíces tejen en el bosque. Un relato que habla de lo viviente y de la potencia de variación de los cuerpos, y que muestra cómo el afecto es "un índice del poder de un determinado cuerpo o combinación de cuerpos" y también "un indicador de la intensidad de un encuentro particular" entre cuerpos que causa en ellos conmoción e impacto (Beasley-Murray 2015, 386-7). Aquí el “encuentro particular" acontece entre la cultura y la naturaleza, la arquitectura y la micología, lo humano y lo vegetal. La "máquina de habitar" como proyecto moderno que hace de la casa un espacio de implementación y visibilización de los criterios, herramientas y necesidades modernos, se desterritorializa y desborda para arruinarse, "hundirse en el cuerpo mineral de la tierra" y aliarse con sus moléculas vivientes y con la incomunicabilidad de sus dinámicas. Al abandonar la villa inhabitable por el goteo incesante del agua que la invade ("la lluvia golpea hacia adentro, incesante". Goldberg 2013, 64), Madame Savoye elige fugarse del mundo a "un reino aparte" —el de los hongos - como una acción radical de resistencia al saber de la historia y a su pretensión de imponer un orden lineal y continuo a la vida. Se aísla, se encierra ("ha descartado todo roce", 94), se contagia con la humedad de la casa, con los restos de un proyecto que fracasó y se convierte en un or- 
ganismo fúngico, en un cuerpo que va despojándose de sus propias partes y se va llenado de una vitalidad tóxica y destructiva: "Hurga en su cuerpo buscando pequeñas costras que arranca sabiendo que volverán a crecer y podrá de nuevo arrasarlas. Extrae también la cutícula de las uñas, la piel muerta de las plantas de los pies, cualquier floración del rostro. Desea erradicar lo impuro, lo sobrante. Lo hace desde niña. Antes sangraba. Ya no" (41). Este cuerpo que se quita partes, que opera para su reducción, "albergaba malignidades inaguantables" desde la infancia y lo "vaciaron de cuajo" a través de una "histerectomía" (80). Con los años y la vejez, se desorganiza y despersonaliza para poblarse de focos infecciosos e intensidades afectivas que producen en él múltiples devenires: "sus manos han decrecido llenas de manchas. Los surcos del rostro hospedan una segunda piel, mucho más áspera y escamosa. Sus facciones [...] son las de un feto [...] la mandíbula se le desencaja con las palabras más largas [...] Ha dejado de maquillarse. Se asea poco, a veces tan solo con un paño húmedo" (100). Madame Savoye arranca de su cuerpo el organismo como estructura que le da significación y orden a la vida, y lo abre a nuevas conexiones y agenciamientos ${ }^{8}$ que producen una regresión e involución en su cuerpo y que funcionan como fuerza de interrupción de la casa como "principio" y "fundamento", como institución establecida, como espacio de arraigo y pertenencia humano, para dejarse ir hacia un afuera molecular y no-humano, prediscursivo, hacia una despersonalización en la que deviene partícula viviente, materia no formada que circula más allá del régimen instituido e higiénico de la vida y que está poblada de intensidades de dolor, decepción, temor, incertidumbre que se alían con las criaturas vegetales que crecen para la muerte.

Este devenir-vegetal de la protagonista comienza en la infancia, cuando pasaba tardes enteras del verano buscando setas en el bosque:

8. Dicen Deleuze y Guattari: "Deshacer el organismo nunca ha sido matarse, sino abrir el cuerpo a conexiones que suponen todo un agenciamiento, circuitos, conjunciones, niveles y umbrales, pasos y distribuciones de intensidad, territorios y desterritorializaciones medidas a la manera de un agrimensor. En última instancia, deshacer el organismo no es más fácil que deshacer los otros estratos, significancia y subjetivación. [...]. Arrancar la conciencia del sujeto para convertirla en un medio de exploración, arrancar el inconsciente de la significancia y la interpretación para convertirlo en verdadera producción, no es seguramente ni más ni menos difícil que arrancar el cuerpo del organismo" (1994, 164-5). 
Sus vacaciones de infancia en la campiña zozobraban en la promesa de largas tardes goteando la hierba y los árboles. Pero la memoria de almuerzos forjados tras la colecta apenas se parecía a la sublimidad. A los diez años vio morir a su amiga Georgette después de llevarse a la boca uno de los hongos que juntas habían recogido. Era una oronja verde, extraviada entre champiñones anisados. (15)

La muerte de la amiga, a causa del veneno de una seta, funda la alianza entre Madame Savoye y lo viviente no-humano: el poder de destrucción de una pequeña criatura vegetal, el deseo de comer la destrucción determinan su vida hasta su muerte: "En su temprana calistenia de la tragedia, tuvo suerte en no toparse jamás con otra oronja verde o con una Ramaria elegante. La habría engullido sin perturbarse por el desenlace. ‘¿Por qué Georgette y no yo?’, se cuestionó ante el cuerpo agonizante de la frágil amiga. Y no dejaría de hacerlo setenta años después” (16).

A partir de este hecho situado al principio de la vida de Madame Savoye, la presencia de la hierba mala y de las setas atormentará su vida como un espectro que regresa para reclamar su incumplimiento. En muchos capítulos de la novela encontramos pasajes donde se pone de manifiesto su deseo de ingerir el cuerpo venenoso de una Amanita phalloides: "La atormenta una oronja verde pero sobre todo las grietas de la casa vacacional $[\ldots]$. Es el recuerdo de la destrucción. Lo irrecuperable. La definitiva desesperanza" (19); "Retorna un hambre de setas salvajes. Aún es verano. [...]. Cree que no soportará el acabose que antecede a toda hechura, por eso las setas, su amargo pálpito [...]" (43); "Piensa en oronjas verdes" (69); "Viene a su boca el sabor mineral de una seta" (88); "He vuelto a pensar en oronjas verdes" (107).

La presencia espectral de este cuerpo vegetal da cuenta de una existencia que busca desmarcarse del reparto de lo sensible moderno a pesar de la posesión de la mujer de una villa realizada según el concepto arquitectónico más vanguardista de la época. Madame Savoye perfora los muros de la máquina de habitar de Le Corbusier y apuesta por la destrucción como resistencia a la seguridad y comodidad que el proyecto moderno quiere garantizar sin lograrlo plenamente. En este sentido, en la novela lo vegetal posibilita fugarse de la concepción biopolítica de la vida hacia otros modos de lo viviente, donde los afectos circulan por intensidad, inmersión, mixtura (Coccia 2017), lo que desencadena otro modo-de-estar-en-el-mundo a partir del agenciamiento de la mujer con la tierra, las raíces, los hongos: 
Mi fin ha sido muy largo. Empezó con una oronja verde. ¿Sabe que hay setas mortíferas? ¿Sabe que un bocado basta para clausurar un soplido? [...] En estos años no he hecho otra cosa que recapitular. Mil veces me he contado. Me sé de memoria. Estoy harta de mí, tanto que a veces introduzco un recuerdo. No invento, solo restituyo lo aplazado, lo injustamente olvidado. Como las setas. Todo en mi vida tiene que ver con setas. Las venenosas y las dulces. Las que probé por gusto y por destino. En mi casa de Poissy no verá setas. Nunca las hubo. Trufas sí, compradas para la cena. Usted no sabe de trufas, su delicadeza es ancestral, como si succionara savia del árbol de la vida. La oronja verde también es dulce, me lo dijo Georgette luego de haberla comido. O no sé si lo imaginé. Eso quizá puedo contárselo en el camino de regreso. Pero no se preocupe, es una historia que acaba pronto. (Goldberg 2013, 131)

Al final de Las horas claras ocurre el encuentro entre la mujer y la oronja, hecho que genera una unión contra-natura entre lo humano y lo vegetal, un vínculo inter species; es decir, la constitución de otro cuerpo y de otra sensibilidad que pierde el nombre propio, el rostro, la especie y se compone de movimientos y velocidades que conectan los vectores afectivos de ambos cuerpos para que uno destruya al otro. ${ }^{9}$ Madame Savoye regresa a la villa después de haber postergado esta decisión por numerosos años y encuentra que la casa que había tenido que abandonar por una avería estructural, que durante la guerra fue ocupada por los alemanes y después expropiada y reparada, se ha convertido en un espacio de germinación de setas mortíferas. Esto implica el devenir-hongo de la máquina de habitar asediada por la energía vital de la naturaleza y su veneno; y el devenir-oronja de la mujer que vuelve a Las horas claras para morir porque muerde el fruto de la destrucción - de sí misma y de la casa como promesa de pertenencia- para introducirlo en su organismo, lo que desencadena una intoxicación irreparable y "la marejada de la muerte" (13):

Madame Savoye descubre, junto a ella, una oronja verde. Incandescente, como nacida en los claros de un antiquísimo pinar. Enorme sombrero, muy plano, largo cuello.

9. Gabriel Giorgi y Fermín Rodríguez observan en el "Prólogo" de Ensayos sobre biopolítica. Excesos de vida: "No se trata de la vida de alguien, sino un flujo de pura vida despojada de su soporte humano que a la manera de una última ola en los límites del mar, borra de la arena el rostro del hombre, llevándose, en su reflujo, percepciones y afectos flotantes impersonales que ya no pertenecen a nadie" (Agamben 2007,16$)$. 
Le Corbusier, asomado en la ventana de la casa del jardinero, sostiene una tetera y un lápiz. No se sorprende ante la presencia de Madame Savoye. Tampoco ella de la suya. Dice él que hay oronjas en la Villa, que desde que fue expropiada aparecieron por doquier: Pruébelas son muy dulces, saben a claridades.

Madame Savoye arranca la oronja, la muerde.

Pregunta, absorta en la serenidad que viene del frío: ¿quién cuida ahora mi casa? (141)

Las horas claras es la historia de la vida y de la muerte de una mujer; también es el relato de la construcción y destrucción de la modernidad y de la disputa entre cultura y naturaleza. En ambos casos, y esto es lo que la novela de Goldberg también nos muestra, la literatura es el lugar donde la vida se vuelve una "singularidad irreductible" a cualquier expresión verbal al escribir en los límites del lenguaje y en contra del lenguaje. La literatura es la hierba que está entre las cosas como flujo que conecta y vincula estados y cuerpos, para dar cuenta de la variación de lo viviente y de otros modos de la comprensión que no pasan por los órdenes epistémicos logocéntricos, sino que atraviesa la tierra y sus proliferantes raíces. $*$

\section{Lista de referencias}

Agamben, Giorgio. 2007. "La inmanencia absoluta". En Ensayos sobre biopolítica. Excesos de vida, compilado por Gabriel Giorgi y Fermín Rodríguez, 59-92. Buenos Aires: Paidós.

Andermann, Jens. 2011. "Tesis de la metamorfosis". Boletín (Centro de Estudios de Teoría y Crítica Literaria). Diciembre. 16. https://www.lopezlabourdette. com/pdf/andermannTesis.PDF.

Beasley-Murray, Jon. 2015. "Biopolítica bolivariana". En La política encarnada. Biopolitica y cultura en la Venezuela bolivariana, editado por Luis Duno, 38597. Caracas: Editorial Equinoccio.

Coccia, Emanuele. 2017. La vida de las plantas. Una metafísica de la mixtura. Buenos Aires: Miño y Dávila Editores.

Contreras, Sandra. 2018. "La pulsión documental o qué cosa es ser realista". Revista N. Clarín. 22 de agosto. https://www.clarin.com/revista-enie/literatura/pulsion-documental-cosa-realista_0_Hy6RTXj8m.html.

Deleuze, Gilles, y Félix Guattari. 1994. Mil mesetas. Capitalismo y esquizofrenia. Valencia: Pre-textos.

Escobar, Ticio. 2014. El arte fuera de sí. Asunción: CAV, Museo del Barro.

Garramuño, Florencia. 2015. Mundo en común. Ensayos sobre la inespecificidad del arte. Buenos Aires: Fondo de Cultura Económica. 
Giorgi, Gabriel. 2014. Formas comunes. Animalidad, cultura, biopolitica. Buenos Aires: Eterna Cadencia.

Goldberg, Jacqueline. 2007. Verbos predadores. Caracas: Editorial Equinoccio/ Universidad Simón Bolívar.

—. 2013. Las horas claras. Caracas: Sociedad de Amigos de la Cultura Urbana.

—. "Jacqueline Goldberg y Las horas claras". https://www.youtube.com/watch?v=fJRjJRyzQAM\&t=1092s.

—. Las horas claras. Blog. http://las-horas-claras.blogspot.com/.

Gomes, Miguel. 2017. El desengaño de la modernidad. Cultura y literatura venezolana en los albores del siglo XXI. Caracas: Abediciones / UCAB / Universidad Católica Andrés Bello.

Moraña Mabel. 2012. "Postscríptum. El afecto en la caja de herramientas". En El lenguaje de las emociones. Afecto y cultura en América Latina, editado por Mabel Moraña e Ignacio Sánchez Prado, 313-38. Madrid-Frankfurt: Iberoamericana / Vervuert.

Nascimento, Evando. 2016. "Para un concepto de literatura en el siglo XXI: expansiones, heteronomías, desdoblamientos". En El lugar de la literatura en el siglo $X X$, editado por Juan Pablo Hormazábal, Josefina Rodríguez y Nicolás Vicente, 47-88. Santiago de Chile: Ediciones Universitarias de Valparaíso, colección Dársena Estudios.

Ocampo, Victoria. 1982. Autobiografía IV. Viraje. Buenos Aires: Sur.

Payares, Gabriel. 2014. "Jacqueline Goldberg: la casa es lo único que nos queda”. PRODAVINCI. 13 de agosto. http://historico.prodavinci.com/blogs/ jacqueline-goldberg-la-casa-es-lo-unico-que-nos-queda-por-gabriel-payares/.

Pogue Harrison, Robert. 2017. Giardini. Riflessioni sulla condizione umana. Roma: Fazi Editore.

Simmel, George. 2002. "Las ruinas". En Sobre la aventura, 181-93. Barcelona: Ediciones.

Speranza, Graciela. 2012. Atlas portátil de América Latina. Arte y ficciones errantes. Barcelona: Anagrama.

Tsin, Anna. "Cómo amar a un hongo". https://elmalpensante.com/articulo/3519/como_amar_a_un_hongo. 